\section{On dotty letters}

SIR - It gives your readers, I suppose, some light relief when you publish dotty letters on improbable ways of achieving peace in our time. Grey Dimond's letter (Nature 15 July, p.220) on the merits of an exchange of marriageable young men and women in attractive uniforms between the Soviet Union and the West has, however, a sound basis despite the more fantastic embellishments.

In the past three years or so, roughly the period since the Soviet invasion of Afghanistan and the intensification of the cold war, the numbers of people visiting the Soviet Union from the United Kingdom have increased. So too have the numbers of Soviet citizens visiting Britain - largely in parties of 500 to 700 on cruise ships and staying for only three or four days. Though the British government signs every two years an agreement with the Soviet Union which includes a commitment to facilitate cultural, scientific and educational exchange, it sometimes obstructs exchange, and paradoxically this has been happening just when it is most needed. In addition to the severe restrictions on Soviet citizens wishing to travel abroad, those who manage to obtain external passports often have much difficulty in getting UK entry visas. Travel in either direction may also have been restricted by cutting to about half by a British government body early last year of the number of flights permitted each week between the United Kingdom and the Soviet Union - primarily for commercial reasons.

Exchanges are vital precisely because of our differences with the Soviet Union. Whether the aim of a visit be business, scientific exchange, tourism, diplomacy or nuclear disarmament, there is bound to be an educational aspect, an adjustment on either side, however slight, of perceptions and understanding of the cold war enemy, and this can only be for the good.

\section{London N6, UK}

Stewart BritTEN

\section{Japanese IQ}

SIR - Regarding possible causes of Japanese children showing a significantly higher IQ than their US and European counterparts, Magyar (Nature 17 June, p.532) suggested that exposure to written Japanese might play a role. I should like to point out, however, that the spoken rather than the written form of Japanese language has been found to be responsible for a characteristic, epigenetic lateralization of auditory processing in the two cerebral hemispheres of native Japanesespeakers regardless of the ethnic identity 1.2 (but do not be misled by ref. 3 based on a complete misunderstanding of the subject). In this respect, both Koreans and Chinese exhibit the same type of lateralization as do Europeans whereas the Japanese and Polynesians belong to a minor group with a different type of lateralization. A hypothesis attempting to relate IQ differences to the first language spoken during childhood could be tested with populations in Taiwan and South Korea - both of which have recently experienced remarkable leaps in economic growth.

Bhargava (Nature I July, p.8), on the other hand, suspects that a quick democratization of education accompanying economic improvement may have been responsible for the very high IQ of Japanese children. However, literacy among the Japanese had perhaps attained a level of 45 per cent for the male and 15 per cent for the female population by the mid-nineteenth century, and at the beginning of the twentieth century practically all children in Japan were attending primary school $^{4}$. This would indicate that the Japanese were not very much behind the Europeans in terms of literacy, and that democratization of education in Japan was neither rapid nor very recent, as suspected by Bhargava. After the war, however, competition among the young Japanese for opportunities of higher education was very much intensified. Competition now starts very early - even at the entrance examination for "elite" kindergartens which will facilitate later competition for higher education in "good" universities promising a good income and a career of life-long commitment. It is therefore conceivable that fierce competition rather than democratization in education is a more likely cause of the higher IQ among Japanese children. The IQ of Japanese children who have attended, for a number of years, Japanese schools overseas (as in London or Sydney) - and in an atmospherc much less competitive than that in Japan - could well be used to test the point A. Sibatani CSIRO Molecular and Cellular Biology Unit, Sydney, NSW, Australia

1. Tsunoda $r$. Nipponjin no (Taishükan, 1978)

2. Sibatani, A. J. Social Biol. SIruct. 3, $255(1980)$

3. Miller. R.A. Japan's Modern Myth (Wcathcrhill. Now York. 1982).

4. Reischauer, H.O). The Japanese (Harvard University Pres, 1977).

\section{Disarmament ideas}

SIR - Among the many documents presented to the UN General Assembly at its Second Special Session on Disarmament (7 June-10 July) was one from the Medical Association for Prevention of War (MAWP) containing a completely new proposal. This calls for "a comprehensive ban on all methods and means of warfare specifically designed to kill or injure by inducing human disease, as distinct from causing mechanical and/or thermal effects". The starting point for the proposal is not the usual one of weapon-types, but the type of effect of weapons on people. The distinction between disease-inducing and mechanical or thermal effects has to be defined for the disarmament diplomats. This can be done in terms of pathology and, in lay terms, by the contrast of disease-inducing for living things only with the similarities of mechanical and thermal effects on animate and inanimate.

The MAPW proposal builds on existing agreements and negotiations on chemical, biological and toxin, and "radiological" weapons; and on agreed prohibitions on the release of "dangerous forces" from nuclear electrical generating stations, the use of environmental modification techniques for hostile purposes, and the use of conventional weapons that leave fragments in the body which are undetectable by $X$ rays (so hindering their surgical removal and hence enhancing the risk of infection). The proposed comprehensive ban would close loopholes in the existing agreements and extend the range of prohibitions - notably by including "neutron" weapons.

Moreover, the proposal opens up a new approach to the question of a comprehensive disarmament programme. The established approach is across-the-board disarmament of all varieties of military power. Modern versions (the United States' and the Soviet draft programmes of 1962 and the draft programme considered by the Special Session) envisage across-the-board comprehensive disarmament in three stages. This is like eating a cake in layers, and it is a proven failure.

The MAPW approach is like eating a mango. The whole of the skin ("diseasemaking") is peeled off first. Successive bites or cuts into the fruit can be flexible in position, size and depth. A comprehensive ban on thermal attacks on people might follow naturally from the ban on "disease-making" (If it is impermissible to inflict disease on one's enemies, one also ought not to burn them.) Reduction in the global total of the nuclear arsenals to below the theoretical level that poses a threat of species' genocide might be the next step. A prohibition on the development of any new weapons of mass destruction should be achieved without difficulty, as discussions on this subject are already in progress. Complete nuclear disarmament might have to await the introduction of objective principles for fixing ceilings on military manpower and expenditure. Current implications are that these should be proportional respectively to population size and gross national product (GNP). MAPW has found that this would have little overall effect on the present global maldistributions, which could be considerably improved, however, if the maximum permitted levels of military manpower and expenditure were made proportional to the square roots of populations and GNPs respectively.

The MAPW approach to comprehensive disarmament does not aspire to the ultimate UN objective of "general and complete disarmament". It leaves behind a hard core of national conventional military power. The hope must be that, having eaten the fruit, the world would decide that the only thing to do with the stone is to throw it away.

JEFFREY SECiALL

Medical Association for Prevention of War, London NW2, UK

\section{Units rule OK?}

SIR - We view the recent letter by H.H. Rossi (Nature 22 July, p.320) with some disquiet. Are we witnessing the beginning of a trend towards the more widespread adoption of that Worrying Hardy Annual, The Nameless Or Unqualified Number In Today's Science (WHAT NO UNITS)?

While recognizing the practical value of bare figures for purely personal or even small group use, we believe that in all published work Units Nevertheless Incorporate Total Simplicity Regarding Unequivocal Literate Expressions Of Knowledge (UNITS RULE OK).

V.R. O'SUllivan W.A. CIIRTIN G.F. KAAR

Department of Anatomy, University College.

Cork, Ireland 